\title{
Pride Park: from redevelopment of a landfill site to long-term operational experience
}

\author{
A. T. Palmer ${ }^{1} \&$ L. Stroud ${ }^{2}$ \\ ${ }^{I}$ Alpheus Environmental Ltd, UK \\ ${ }^{2}$ Arup Ltd, UK
}

\begin{abstract}
The Pride Park site outside Derby had a legacy of contamination as a result of its industrial past. The site was previously used for industrial and domestic landfill, a gas works, railway sidings and gravel extraction. In the mid-1990s the site was closed and the heavily contaminated derelict land was remediated to allow site redevelopment. The work, undertaken by Ove Arup \& Partners, Purac-Morrison and Alpheus Environmental included: a $10 \mathrm{~m}$ deep, $3 \mathrm{~km}$ long cut-off wall encircling the site to prevent contaminant migration; 18 abstraction boreholes within the cut-off wall and linked to a ring main; a treatment plant receiving groundwater from the ring main and providing treatment prior to discharge to the River Derwent; and 18 pairs of monitoring boreholes to check groundwater levels inside and outside the cut-off wall to ensure that a level differential was maintained. Alpheus Environmental has operated and maintained the leachate treatment plant and associated boreholes on behalf of Derby City Council since late 1997. The treatment plant consists of an aerated balance tank, a flocculation/clarification stage with polyelectrolyte and ferric addition, $\mathrm{pH}$ correction, biological nitrification, sand filter, sludge belt press, on-line monitors and telemetry. The on-line monitors enable automatic borehole pump shutdown and recirculation of effluent within the plant in the event of specification limits being exceeded. Over the years effective management and implementation of a monitoring programme have enabled a significant reduction in operating costs for the client. These include over $25 \%$ reduction in electricity costs and $80 \%$ reduction in analytical and chemical costs.
\end{abstract}

Keywords: landfill, remediation, groundwater treatment, operating costs. 


\section{Introduction}

Pride Park, located a short distance south east of Derby city centre, was the site of the city's former gas works, a municipal landfill, a British Rail locomotive depot and a former industrial works. In 1992, Derby City Council identified the 82 hectare site as heavily contaminated and wished to develop the land with support from the Government City Challenge scheme.

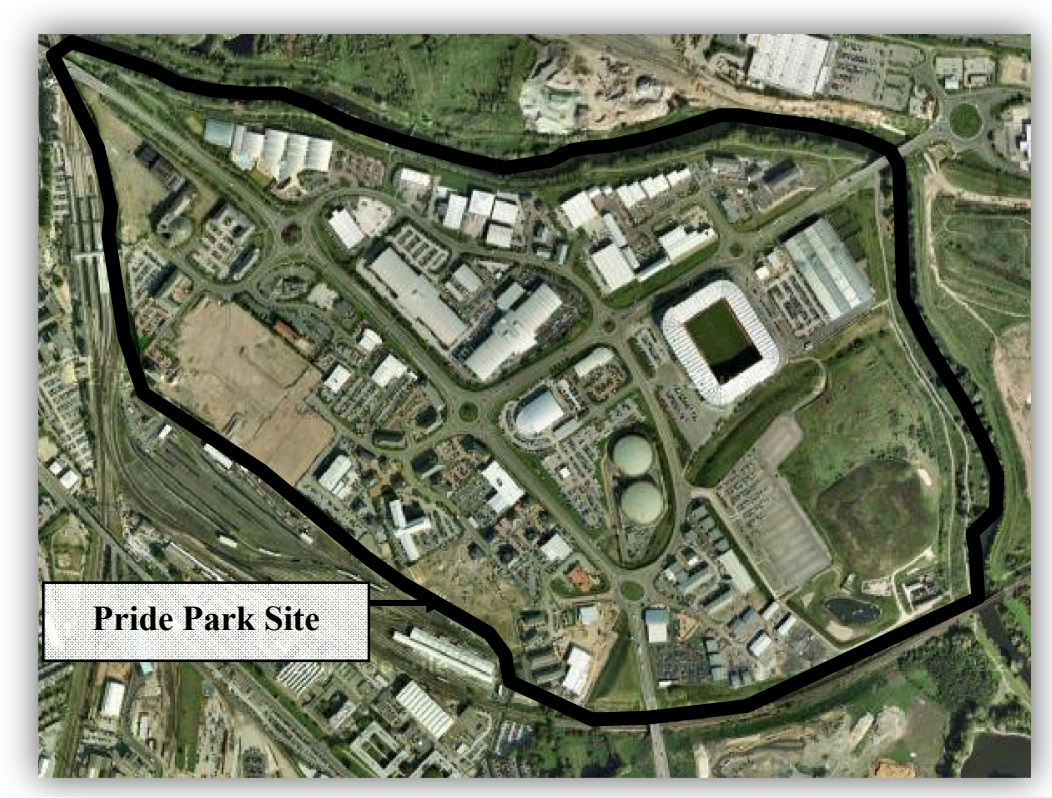

Figure 1: $\quad$ Aerial view of the Pride Park Site [1].

City Challenge was a national initiative implemented in different local circumstances. Its aim was to bring sustainable and integrated regeneration to areas of widespread and multiple deprivations. City Challenge allocated $£ 37.5 \mathrm{~m}$ over five years to each of the 31 Urban Programme authorities to achieve selfsustaining regeneration of their designated City Challenge areas. The funds were allocated on the basis of two competitions. In the first round, 17 local authorities covering 15 areas were invited to compete for City Challenge status. They were chosen to represent a wide range of differing circumstances across the country. The scheme emphasised not just physical regeneration but improvements that could be made to economy, social infrastructure, communities and the local quality to life. 


\section{Site remediation}

\subsection{Background}

Arup was commissioned in 1993 by Derby City Council to design and supervise the implementation of phased reclamation of the Pride Park site, to allow commercial, light industrial, retail and leisure development. The scope of work included desk studies, site investigations, risk assessments, consultation with statutory authorities, detailed design and specifications, in situ remediation trials and construction supervision. Since the site has been developed Arup has been managing the monitoring programmes for the water treatment plant and two engineered landfills that were constructed on the site to house the worst of the contaminated soil.

\subsection{Contamination}

The type and concentrations of contamination encountered were typical of a landfill constructed during the 1950s and 1960s. Elevated levels of sulphate and sulphides and some of the heavy metals associated with the widespread presence of ash and clinkers within the fill, resulted from the common practice to dispose of waste from domestic fossil fuels as domestic waste in landfills at that time. Other heavy metals and cyanides were associated with the disposal of surplus materials and arising from the demolition of the nearby Litchurch gasworks during the late 1970s and early 1980s.

Contaminants in groundwater in the Terrace Gravels below the site derived partly from contaminants in the overlying waste and partly from groundwater migrating from the west. Samples of groundwater taken from the gravels from nearby standpipes during early site investigations indicated elevated levels of cadmium, lead, mercury, nickel, cyanide, sulphate, ammonia and phenols.

The drift geology underlying Pride Park comprises River Terrace Gravels and Alluvium, overlying strata of the Triassic Mercia Mudstone. The drift deposits are overlain by a thickness of Made Ground relating to the site's previous use as a refuse tip. The Made Ground found in the former tip has been assessed in two broad categories: granular fill materials and domestic and industrial waste.

\subsection{Reclamation strategy}

The eastern part of the Pride Park site was used for tipping domestic and industrial refuse since the 1940s when an oxbow lake was infilled. In 1982 disposal of inert material from the construction industry commenced and this ceased in the early 1990s.

A key part of the strategy was to split the site into eastern and western halves. Due to the depths at which highly contaminated material was identified and the proximity to the River Derwent, a $3 \mathrm{~km}$ long and $10 \mathrm{~m}$ deep bentonite cut-off wall was installed around the eastern half of the site to prevent the contaminated groundwater from entering the river. 
A fundamental aspect of the bentonite wall was that groundwater levels within the wall were to be kept below the groundwater level outside of the wall to ensure that, in the event of damage to the wall's membrane, the groundwater movement direction would be from outside to inside the wall. Nineteen pairs of monitoring wells were installed inside and outside of the wall perimeter to check water levels.

In addition, 18 abstraction wells were installed adjacent to the wall to maintain the groundwater levels within the wall. The wells are linked to a ringmain and groundwater is pumped to a water treatment plant in the south-eastern corner of the Pride Park site for processing prior to discharge to the River Derwent.

\subsection{Waste repositories}

Areas of highly contaminated material were also found in the western part of the site. These were removed and placed within one of two on-site disposal facilities or 'waste repositories' now known as WR1 and WR2. Boreholes from around the two waste repositories are subject to scheduled monitoring and are licensed under the Environmental Permitting Regulations, with annual monitoring reports submitted to the Environment Agency (EA) under the terms of these licenses.

Arup's remediation strategy argued that because of the containment wall and treatment plant, parts of the original domestic landfill could remain in situ. The proviso was that reclamation strategy also included a gas venting trench sited along the northern margin of this "old landfill" area.

\subsection{WR1 / WR2}

Waste repository 1 (WR1) was designed to accept contaminated material from the first phase of reclamation and was completed in 2000. WR1 is located on the site of an old landfill and within the area enclosed by the bentonite cement cutoff wall, in the southern part of the Pride Park site.

The ongoing monitoring in and around WR1 includes eight gas and groundwater monitoring wells (BH1-BH8) located around the periphery of Waste Repository No.1. The boreholes were constructed in June 1997 to depths of between $6.3 \mathrm{~m}$ (BH5) and $12.5 \mathrm{~m}$ (BH2) below surface, with each borehole terminating at the junction between the Terrace Gravels and the Mercia Mudstone. Two boreholes (BH4 and BH5) were positioned outside the cut-off wall to provide a reference for background gas and groundwater concentrations throughout the period of monitoring.

The construction of WR2 was completed in December 2003 and it included:

- eight groundwater monitoring wells located outside the repository to give adequate coverage of groundwater both up and down hydraulic gradient (W1 to W8);

- four gas monitoring wells spaced evenly around the repository footprint (G1-G4);

- two surface water monitoring points on the River Derwent, one upstream (L1-L5) within the waste; 
- four leachate detection manholes (LDS1-LDS4) to measure potential leachate leakage, and;

- a leachate tank, designed to collect the leachate to allow an assessment of annual leachate volume and quality.

\section{Water treatment plant}

\subsection{The design and consent parameters}

Designed and built by the Purac-Morrison consortium, the water treatment plant was commissioned in 1997. It consists of two aerated balance tanks followed by a flocculation and clarification stage (Figure 2). Anionic polyelectrolyte and flocculant are dosed to the flocculation stage to remove dissolved metals and suspended solids (SS). The effluent is nitrified in two parallel Kaldnes moving bed biological reactors with coarse bubble aeration. The effluent is then passed

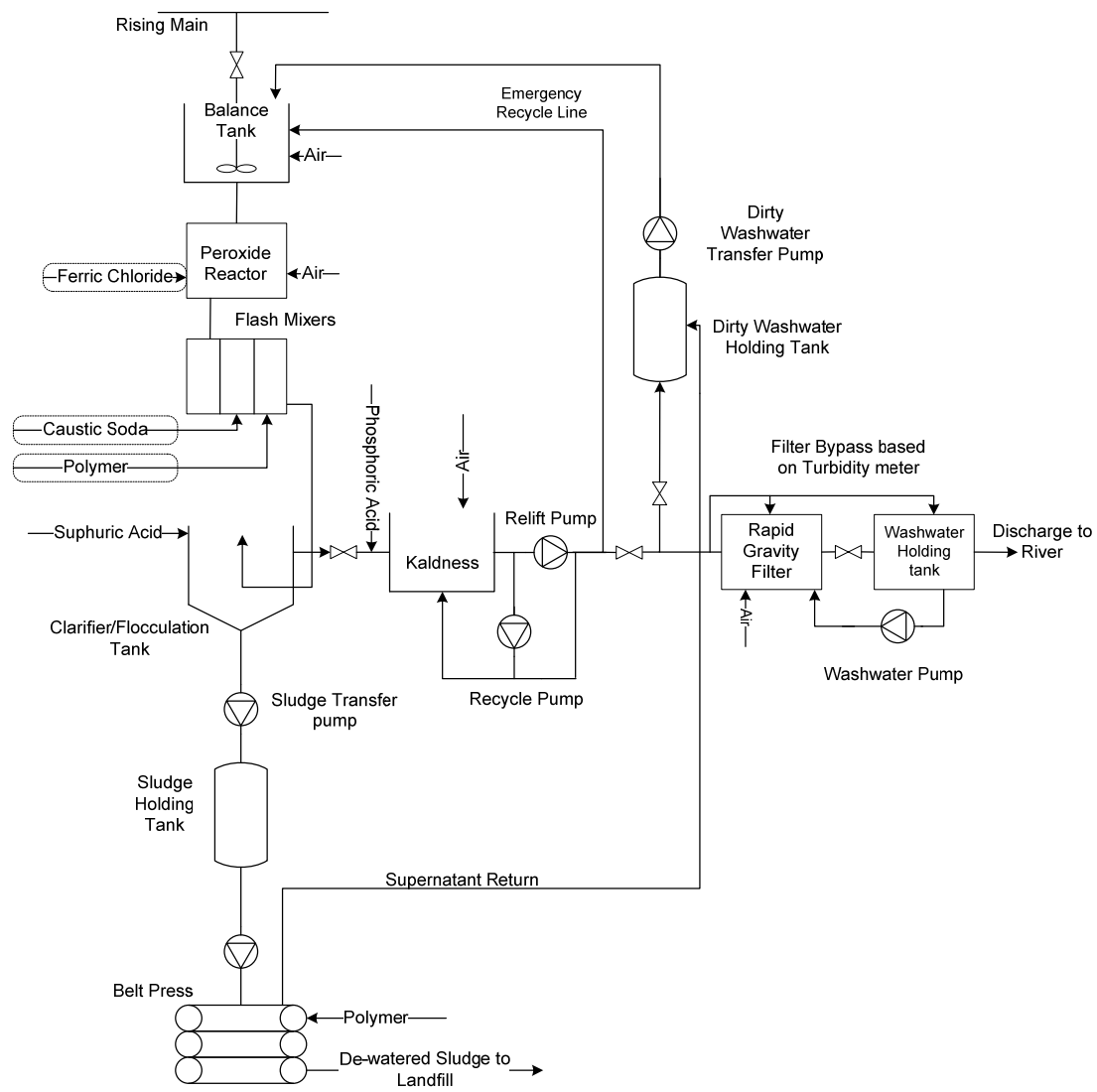

Figure 2: $\quad$ Flow diagram of the water treatment plant. 
through a sand filter to remove fine solids prior to discharge to the River Derwent. The sand filter is automatically backwashed at regular intervals and the solids are returned to the head of the plant. Waste sludge is drawn from the clarifier and stored in a sludge tank prior to thickening in a sludge belt press with the aid of polyelectrolyte. The sludge cake is stored in a skip for off-site disposal in a licensed facility. The liquid from the sludge belt press is returned to the head of the treatment plant.

The plant was designed to the maximum values shown in Table 1 to meet the discharge consent for over 60 parameters. It is highly automated in order to run $24 / 7$ and telemetry is used to alert of high levels or key equipment failure. A number of parameters are measured continuously and logged at $10 \mathrm{~min}$ intervals. Dissolved oxygen (DO) is measured in the Kaldnes reactors, inlet and outlet streams. In the inlet and outlet streams also $\mathrm{pH}$, total organic carbon (TOC), ammonia, conductivity and flow are recorded. If the parameters for the final effluent exceed the pre-set limits the abstraction well pumps automatically switch off and the effluent is re-circulated within the plant.

Table 1: $\quad$ Examples of the design values.

\begin{tabular}{|c|c|c|}
\hline Parameter & Maximum value & Maximum load \\
\hline Flow rate & $331 / \mathrm{s}\left(2,860 \mathrm{~m}^{3} / \mathrm{d}\right)$ & - \\
\hline Biochemical Oxygen Demand (BOD) & $15 \mathrm{mg} / \mathrm{l}$ & $24 \mathrm{~kg} / \mathrm{d}$ \\
\hline Chemical Oxygen Demand (COD) & $120 \mathrm{mg} / 1$ & $152 \mathrm{~kg} / \mathrm{d}$ \\
\hline Suspended solids (SS) & $800 \mathrm{mg} / 1$ & $200 \mathrm{~kg} / \mathrm{d}$ \\
\hline $\mathrm{pH}$ & $6.5-8.5$ & - \\
\hline Ammonia & $50 \mathrm{mg} / 1$ & $120 \mathrm{~kg} / \mathrm{d}$ \\
\hline Iron & $3 \mathrm{mg} / 1$ & - \\
\hline
\end{tabular}

\subsection{Operation of the abstraction wells}

The abstraction wells and the water treatment plant have been operated and maintained by Alpheus Environmental Ltd since 1997. This set up has enabled a close control of the operations and optimisation where necessary.

The abstraction wells were initially recorded monthly to establish the groundwater volumes that the water treatment plant would receive. The wells were also sampled annually for a number of parameters including metals and organics. The contamination levels in the groundwater reduced over time although they were expected to increase again as the more contaminated areas were developed. The abstraction wells were pumped based on the groundwater levels and ammonia concentrations. The wells from the oldest part of the landfill contained low ammonia (1-50 mg/l) and were continuously pumped. Other wells with high levels of ammonia (150-250 mg/l) were pumped intermittently. From 2006 onwards ammonia concentrations below $100 \mathrm{mg} / \mathrm{l}$ have consistently been measured in all the abstraction wells, enabling the wells to be pumped based on supply and demand. 
The water quality and level in the monitoring wells are checked regularly for indications of possible failures in the integrity of the bentonite wall and contamination of water from inside the wall to outside. The results do not have an impact on pumping from the abstraction wells. The required level differential has been maintained around the site except for some quite pronounced seasonal variations along the river boundary.

The abstraction wells have been redeveloped every few years when the pump flow rates and borehole recharge times have become significantly slower than in the nearby boreholes. The method involves dosing of sodium hypochlorite and jetting the boreholes to remove deposit. In most cases the recharge times and flow rates have improved following this procedure.

\subsection{Operation of the treatment plant}

During the plant commissioning in late 1997 major changes were observed in the groundwater quality. Notably ammonia and iron concentrations exceeded the values used for the plant design and it was evident that changes to the original design were necessary. The chemicals intended to be used at the plant were inefficient and more suitable chemicals were chosen after trials. Limited treatment and slow biomass growth in the Kaldnes units were improved by adding phosphoric acid to the units. Precipitation of carbonate caused the Kaldnes media to sink and this was prevented by adding sulphuric acid to the reactors and reducing the aeration.

The consent for total oxidised nitrogen (TON) in the final effluent limits the amount of ammonia and the volume which can be treated. At the start of the operation it was found that the TON consent of $40 \mathrm{mg} / \mathrm{l}$ would be met if the influent ammonia was around $50 \mathrm{mg} / \mathrm{l}$. This was of concern for two reasons. Firstly due to the widely variable ammonia concentrations in the abstraction wells, and secondly due to the fact that the plant was not designed for denitrification. However, in 2003-2005 denitrification trials were carried out after modifications to the plant. The trials proved successful however the plant was returned to its previous set up after the ammonia levels in the boreholes reduced to below $100 \mathrm{mg} / \mathrm{l}$ and it was possible once more to meet the TON consent.

Up to $24 \%$ dry solids have been achieved by using the sludge belt press with polymer dosing. The sludge belt press and the sand filter are used as and when required when the organic content of the influent is low.

The plant has operated at an average influent flow of 15-20 1/s. The annual volume of treated water has varied between $418,000 \mathrm{~m}^{3}$ and $182,000 \mathrm{~m}^{3}$, gradually decreasing over the years due to the reduced rainfall catchment area in the landfill development. In total over 3.8 million cubic metres of treated effluent has been discharged to the River Derwent to date.

On the whole, the plant has been mechanically and electrically reliable and robust. The main concerns have been the blowers, borehole pumps and monitoring equipment. Equipment is upgraded and replaced as and when necessary. 


\subsection{Influent and effluent quality}

The results presented in this paper are from the period of 2000-11. Samples were initially taken from five key stages of the process for a more complete performance profile: influent, flocculator / clarifier influent, Kaldnes reactor influent, Kaldnes reactor effluent, and final effluent. As the plant performance became stable samples were taken only from the influent and effluent streams.

The plant has performed well despite the fluctuations in the influent groundwater quality and the lower than anticipated loading rates (Table 2). The discharge consent limit has been met throughout the period apart from a few occasions where TON was exceeded.

Table 2: $\quad$ Average loading and influent and effluent quality in 2000-11.

\begin{tabular}{|c|c|c|c|c|}
\hline Parameter & $\begin{array}{c}\text { Loading } \\
\text { (kg/d) }\end{array}$ & $\begin{array}{c}\text { Influent } \\
\text { (in mg/l) }\end{array}$ & $\begin{array}{c}\text { Effluent } \\
\text { (in mg/l) }\end{array}$ & $\begin{array}{c}\text { Discharge } \\
\text { Consent Limit } \\
\text { (in mg/l) }\end{array}$ \\
\hline BOD & - & $3.0 \pm 1.4$ & $2.9 \pm 4.4$ & 10 \\
\hline COD & $11 \pm 6$ & $20.3 \pm 6.1$ & $18.6 \pm 7.6$ & 40 \\
\hline SS & $6 \pm 10$ & $6.9 \pm 8.2$ & $5.3 \pm 9.5$ & 25 \\
\hline Ammonia & $19 \pm 7$ & $30.8 \pm 8.6$ & $1.0 \pm 3.8$ & 3 \\
\hline TON & - & $3.3 \pm 4.0$ & $32.8 \pm 5.0$ & 40 \\
\hline pH & - & $7.3 \pm 0.4 \mathrm{pH}$ units & $7.9 \pm 0.4$ & $6-9 \mathrm{pH}$ units \\
\hline Iron & - & $0.5 \pm 0.6$ & $0.2 \pm 0.2$ & 2.5 \\
\hline
\end{tabular}

\subsection{Operating costs}

In the early years of operation the plant operations were assessed by Alpheus Environmental in detail and areas of improvement identified. A thorough targeting and monitoring programme was planned and implemented stage by stage. This resulted in significant savings in energy, bulk chemicals and sample costs which have all been achieved without compromising the plant performance.

The energy usage has been primarily related to the air blowers and the abstraction borehole pumps. Peaks in energy usage were associated with the high influent volumes in the early years of operation and later with the denitrification trials. The average power consumption per metre cubed of treated water was $1.29 \mathrm{kWh} / \mathrm{m}^{3}$ in $2000-11$. During this period the average power cost was $7.9 \mathrm{p} / \mathrm{m}^{3}$. A reduction of $25 \%$ in energy use has been achieved through measures such as blower output, belt and pulley size adjustment as well as using only one Kaldnes stream when the volumes are lower than designed.

The requirement for bulk chemicals to enhance and enable treatment has varied depending on the influent water quality. The related costs were high especially in 1998-2002 when large volumes of caustic soda, ferric chloride and sulphuric acid were used. As modifications were made to the operation fewer chemicals were used. This reduction in the bulk chemical usage resulted in an 
$80 \%$ saving in total bulk chemical costs, with the chemical consumption cost being $0.80 \mathrm{p} / \mathrm{m}^{3}$ in 2011 .

Initially the sample analysis costs were high due to the frequency and the type of the samples analysed in accredited laboratories. The analysis costs in the onsite laboratory facility were negligible. The sampling frequency was reduced in 2003, 2006 and 2009 following discussions with the Environment Agency on the continually good discharged effluent quality, resulting in an $80 \%$ saving for this element of expenditure.

\section{Conclusions}

Pride Park is a complex contaminated site, remediated by combining an array of treatment processes, including encapsulation, landfilling, attenuation, and water treatment.

The "plot by plot" remediation strategy, kick started by City Challenge incentives, released funding for a rolling programme of clean up at the site. This has become a successful model for the regeneration of many similar large scale sites across the UK. Proactive and engaging dialogue with the EA and other stakeholders has facilitated a web of collaborative relationships between contractors, consultants, the client and regulations. Real cost and programme savings have been made in many different elements of the project, including monitoring programmes, chemical usage and energy consumption.

The water treatment plant at Pride Park has been operational for nearly 14 years and during this time it has treated almost 4 million cubic metres of groundwater. The plant has been successful in achieving the consent limits set by the EA. Significant savings in operational expenditure and improvements in efficiency have been made by Alpheus Environmental during this period.

The challenge for the future operation of the water treatment plant is to continue this balancing act whilst new development takes place gradient on the site and to optimise and maintain the existing infrastructure at a sustainable level.

\section{Reference}

[1] 2012 Digital Globe, Geoeye. Getmapping plc Infoterra Ltd \& Bluesky. http://maps.google.co.uk 